\title{
Testicular Yolk Sac Tumor, Enteric Pattern
}

National Cancer Institute

\section{Source}

National Cancer Institute. Testicular Yolk Sac Tumor, Enteric Pattern. NCI Thesaurus. Code C39932.

A yolk sac tumor that arises from the testis and is characterized by the presence of immature glands. 